\title{
LESSONS FROM A LARGE NATIONWIDE STUDY OF 350 CHILDREN WITH OVARIAN MATURE TERATOMA: A PLEA FOR OVARIAN-SPARING SURGERY
}

Fanny Delehaye ${ }^{1}$, Sabine SARNACKI ${ }^{2}$, Daniel Orbach ${ }^{3}$, Alaa Cheikhelard ${ }^{2}$, Jérémie Rouger $^{1}$, Jean-Jacques Parienti ${ }^{1}$, Cécile Faure-Conter ${ }^{4}$, Frédéric Hameury ${ }^{5}$, Frédérique Dijoud $^{6}$, Estelle Aubry ${ }^{7}$, Agnès Wacrenier ${ }^{8}$, Edouard Habonimana ${ }^{9}$, Camille Duchesne ${ }^{9}$, Solène Joseph ${ }^{10}$, Hortense Alliot ${ }^{10}$, Aurélien Scalabre ${ }^{11}$, Yann Chaussy ${ }^{12}$, Guillaume Podevin $^{13}$, Anne Croué ${ }^{13}$, Elodie Haraux ${ }^{14}$, Isabelle Pommepuy ${ }^{15}$, Quentin Ballouhey ${ }^{16}$, Frederic Lavrand ${ }^{17}$, Matthieu Peycelon ${ }^{18}$, Sabine $\operatorname{Irtan}^{19}$, Florent Guérin ${ }^{20}$, Claude Borionne $^{21}$, Anne Dariel ${ }^{21}$, Louise Roulland ${ }^{10}$, and Julien Rod ${ }^{1}$

${ }^{1} \mathrm{CHU}$ Caen

${ }^{2}$ Necker-Enfants Malades Hospitals

${ }^{3}$ Institut Curie

${ }^{4} \mathrm{IHOPe}$

${ }^{5} \mathrm{CHU}$ Lyon

${ }^{6}$ Hospices Civils de Lyon

${ }^{7} \mathrm{CHU}$ Lille Pôle Enfant

${ }^{8} \mathrm{CHU}$ Lille

${ }^{9} \mathrm{CHU}$ Rennes

${ }^{10} \mathrm{CHU}$ Nantes

${ }^{11}$ CHU Saint-Étienne

${ }^{12}$ CHU Besancon

${ }^{13} \mathrm{CHU}$ Angers

${ }^{14} \mathrm{CHU}$ Amiens-Picardie

${ }^{15} \mathrm{CHU}$ Dupuytren

${ }^{16} \mathrm{CHU}$ Limoges

${ }^{17} \mathrm{CHU}$ Bordeaux GH Pellegrin

${ }^{18}$ Robert-Debré Mother-Child University Hospital

${ }^{19}$ Armand-Trousseau Childrens Hospital

${ }^{20}$ Hôpital Bicêtre

${ }^{21} \mathrm{CHU}$ Timone

April 16, 2021

\begin{abstract}
Objective Ovarian mature teratoma (OMT) is a common ovarian tumor found in the pediatric population. In $10 \%$ to $20 \%$ of cases, OMT occurs as multiple synchronous or metachronous lesions on ipsi- or contralateral ovaries. Ovarian sparing surgery (OSS) is recommended to preserve fertility, but total oophorectomy (TO) is still performed. This study reviews the clinical data
\end{abstract}


of patients with OMT, and analyzes risk factors for second events. Design A retrospective review of all girls under 18 years of age with OMTs was performed. Data on clinical features, imaging, laboratory studies, surgical reports, follow-up second events and their management were retrieved. Results Overall, 350 children were identified. Eighteen patients (5\%) presented with a synchronous bilateral form at diagnosis. Surgery was performed by laparotomy (85\%) and laparoscopy (15\%). OSS and TO were performed in $59 \%$ and $41 \%$ of cases respectively. Perioperative tumor rupture occurred in 23 cases, independently of the surgical approach. Twenty-nine second events occurred (8.3\%) in a median time of 30.5 months from diagnosis (ipsilateral: 8 cases including one malignant tumor, contralateral: 18 cases, both ovaries: 3 cases). A large palpable mass, bilateral forms at diagnosis and perioperative rupture had a statistical impact on the risk of second event, whereas type of surgery or approach did not. Conclusion This study is a plea in favor of OSS as the first choice of treatment of OMT when possible. Close follow-up during the first five years is mandatory considering the risk of $8.3 \%$ of second events especially in cases with risk factors.

\section{LESSONS FROM A LARGE NATIONWIDE STUDY OF 350 CHILDREN WITH OVARIAN MATURE TERATOMA: A PLEA FOR OVARIAN-SPARING SURGERY}

\section{Author names and affiliations:}

DELEHAYE Fanny ${ }^{1}$, SARNACKI Sabine ${ }^{2}$, ORBACH Daniel ${ }^{3}$, CHEIKHELARD Alaa ${ }^{2,4}$, ROUGER Jérémie $^{1}$, PARIENTI Jean-Jacques ${ }^{5}$, FAURE-CONTER Cécile ${ }^{6}$, HAMEURY Frédéric ${ }^{7}$, DIJOUD Frédérique $^{8}$, AUBRY Estelle ${ }^{9}$, WACRENIER Agnès ${ }^{10}$, HABONIMANA Edouard $^{11}$, DUCHESNE Camille ${ }^{11}$, JOSEPH Solène ${ }^{12}$, ALLIOT Hortense ${ }^{12}$, SCALABRE Aurélien ${ }^{13}$, CHAUSSY Yann ${ }^{14}$, PODEVIN Guillaume $^{15}$, CROUE Anne ${ }^{16}$, HARAUX Elodie ${ }^{17}$, POMMEPUY Isabelle ${ }^{18}$, BALLOUHEY Quentin ${ }^{19}$, LAVRAND Frédéric ${ }^{20}$, PEYCELON Matthieu ${ }^{21}$, IRTAN Sabine ${ }^{22}$, GUERIN Florent ${ }^{23}$, DARIEL Anne ${ }^{24}$, BORIONNE Claude ${ }^{25}$, GALMICHE Louise ${ }^{26}$, ROD Julien ${ }^{27,28}$

1 Department of Pediatric Haematology and Oncology, University Hospital of Caen, 14000 Caen, Francef.delehaye@gmail.comrouger-j@chu-caen.fr

2 Department of Pediatric Surgery, Université de Paris, Hôpital Necker Enfants-Malades, Assistance Publique - Hôpitaux de Paris, Paris, France sabine.sarnacki@aphp.fr alaa.cheikhelard@aphp.fr

3 SIREDO Oncology Centre (Care, Innovation and Research for Children, Adolescents and Young Adults with Cancer), Institut Curie, PSL University, Paris, France daniel.orbach@curie.fr

4 National Reference Centre for Rare Gynecological Diseases (PGR), Paris, France. alaa.cheikhelard@aphp.fr

5 Department of Biostatistics and Clinical Research, University Hospital of Caen Normandy, Caen, France parienti-jj@chu-caen.fr

6 Centre Leon Bernard, Pediatric Hemato-Oncology Institute (IHOPe), Lyon, France cecile.conter@ihope.fr

7 Pediatric Surgery Department, Femme-Mère-Enfant University Hospital, 59, boulevard Pinel, 69677 Bron, France frederic.hameury@chu-lyon.fr

8 Anatomy-Cytology-Pathology Department, Women-Mother and Child Hospital, Hospices Civils de Lyon, Lyon, France frederique.dijoud@chu-lyon.fr

9 CHU Lille, Centre de Référence du Développement Génital DEV GEN, Service de Chirurgie Pédiatrique, Hôpital Jeanne de Flandres, 59000 Lille, France Estelle.AUBRY@chru-lille.fr

10 Anatomy-Cytology-Pathology Department, CHU Lille, Lille, France Agnes.WACRENIER@CHRULILLE.FR

11 Department of Pediatric Surgery, Rennes University Hospital, Rennes, France edouard.habonimana@churennes.fr Camille.DUCHESNE@chu-rennes.fr

12 Department of Pediatric Surgery, CHU de Nantes, Hôtel-Dieu, 1, Place Alexis-Ricordeau, 44000 Nantes, France Solene.JOSEPH@chu-nantes.fr hortense.alliot@gmail.com 
13 Department of Pediatric Surgery, University Hospital of Saint-Etienne, CHU de Saint-Etienne Hôpital Nord, Saint Etienne Cedex 2, France Aurelien.Scalabre@chu-st-etienne.fr

14 Paediatric Surgery Department, University Hospital of Besancon, Besancon, France ychaussy@chubesancon.fr

15 Paediatric Surgery Department, Angers University Hospital, Angers, France GuPodevin@chu-angers.fr

16 Anatomy-Cytology-Pathology Department, Centre Hospitalier Universitaire d'Angers, Angers, France ancroue@chu-angers.fr

17 Paediatric Surgery Department, Amiens University Hospital, Amiens, France Haraux.Elodie@chuamiens.fr

18 Service d'anatomie Pathologique, CHU Dupuytren, 2, Avenue Martin-Luther-King, 87042 Limoges Cedex, France Isabelle.Pommepuy@chu-limoges.fr

19 Department of Pediatric Surgery, Hôpital des Enfants, 8 Avenue Dominique Larrey, 87042, Limoges Cedex, France Quentin.Ballouhey@chu-limoges.fr

20 Department of Pediatric Surgery, Groupe Hospitalier Pellegrin, Hôpital d'enfants, Bordeaux, France frederic.lavrand@chu-bordeaux.fr

21 AP-HP, Hôpital Universitaire Robert-Debré, Pediatric Urology Department, Reference Center for Rare Diseases (CRMR), Malformations Rares des Voies Urinaires (MARVU), Université de Paris, Paris, France matthieu.peycelon@aphp.fr

22 Paediatric Surgery Department, Trousseau Hospital - Assistance Publique des Hôpitaux de Paris, Paris, France sabine.irtan@aphp.fr

23 Paediatric Surgery Department, Groupement Hospitalier Paris Sud (GHUPS), Hôpital Bicêtre, Le Kremlin Bicetre, France florent.guerin@aphp.fr

24 Pediatric Surgery Department, Hôpital d'enfants de la Timone, Marseille, France Anne.dariel@ap-hm.fr Claude.LOUIS@ap-hm.fr

25 Pathology Department, CHU de Nantes, Hôtel-Dieu, 1, Place Alexis-Ricordeau, 44000 Nantes, France louise.rolland@chu-nantes.fr

26 Department of Pediatric Surgery, University Hospital of Caen, Avenue de la Côte de Nacre, 14 000, Caen, France rod-j@chu-caen.fr

27 Laboratory INSERM U1086, ANTICIPE, Centre François Baclesse, Caen, France rod-j@chu-caen.fr

\section{Corresponding author}

DELEHAYE Fanny, Department of Pediatric Hematology and Oncology, University Hospital of Caen, Avenue de la Côte de Nacre, 14000 Caen, France. E-mail: f.delehaye@gmail.com; Telephone 0033(0)2.31.06.44.88

Running title : ovarian mature teratoma-sparing surgery

\section{Abstract}

\section{Objective}

Ovarian mature teratoma (OMT) is a common ovarian tumor found in the pediatric population. In $10 \%$ to $20 \%$ of cases, OMT occurs as multiple synchronous or metachronous lesions on ipsi- or contralateral ovaries. Ovarian sparing surgery (OSS) is recommended to preserve fertility, but total oophorectomy (TO) is still performed. This study reviews the clinical data of patients with OMT, and analyzes risk factors for second events.

\section{Design}


A retrospective review of all girls under 18 years of age with OMTs was performed. Data on clinical features, imaging, laboratory studies, surgical reports, follow-up second events and their management were retrieved.

\section{Results}

Overall, 350 children were identified. Eighteen patients (5\%) presented with a synchronous bilateral form at diagnosis. Surgery was performed by laparotomy (85\%) and laparoscopy (15\%). OSS and TO were performed in $59 \%$ and $41 \%$ of cases respectively. Perioperative tumor rupture occurred in 23 cases, independently of the surgical approach. Twenty-nine second events occurred (8.3\%) in a median time of 30.5 months from diagnosis (ipsilateral: 8 cases including one malignant tumor, contralateral: 18 cases, both ovaries: 3 cases). A large palpable mass, bilateral forms at diagnosis and perioperative rupture had a statistical impact on the risk of second event, whereas type of surgery or approach did not.

\section{Conclusion}

This study is a plea in favor of OSS as the first choice of treatment of OMT when possible. Close follow-up during the first five years is mandatory considering the risk of $8.3 \%$ of second events especially in cases with risk factors.

\section{Tweetable abstract}

Ovarian-sparing surgery has to be the first choice to treat ovarian mature teratomas because of possible second events $(8.3 \%)$

Keywords : germ cell tumors, ovarian tumors, mature teratoma, children, conservative surgery

\section{Introduction}

In children, ovarian mature teratomas (OMTs) are usually benign (1). These benign germ cell tumors (GCTs) are characterized by differentiated tissue types originating from 2 to 3 germ cell lineages - the ectoderm, mesoderm and endoderm (2). OMTs represent the most common benign neoplasms among pediatric GCTs, reported in $70 \%$ of females under 30 years of age and making up 30\% to $50 \%$ of all pediatric adnexal lesions (3-10). Even if unilateral OMTs are the most frequent situation at diagnosis, OMT can present as multifocal on ipsi- or contralateral ovaries. Treatment relies on surgery with the aim of obtaining complete tumor resection without recurrence. Nevertheless, the ovarian parenchyma must be preserved when preoperative work-up is consistent with a diagnosis of a benign lesion such as OMT (7). Imaging, particularly MRI plays key role in collecting evidence for the benign nature of the lesion, such as the presence of fat, liquid and calcifications $(7,11)$. When lesions have large volumes (above $20 \mathrm{~cm}^{3}$ or $8 \mathrm{~cm}$ ), notable vascularization, intratumoral septations, papillary projections, heterogeneity or solid tissue echogenicity, ascites, or nodal/distant metastasis, the OMT diagnosis should be questioned, and the specialist should be alerted to a potential malignant tumor $(2,6,9,11-13)$. Differential diagnosis also includes other benign lesions, such as epithelial tumors, which account for $30 \%$ of benign ovarian tumors (10). The challenge for the decision-making process is that malignant nonsecreting GCTs, such as dysgerminoma or, less frequently, sex-cord stromal tumors, such as granulosa juvenile cell tumors, may present similar features to those of OMTs. Tumor markers (alpha-fetoprotein (AFP), human chorionic gonadotropin (HCG), inhibin B, anti-Müllerian hormone (AMH), calcemia) and hormonal dosages in cases of pseudopuberty or dysmenorrhea are key to ruling out malignant lesions $(3,12,14,15)$. In case of doubt, upfront total oophorectomy (TO) is a secure option, avoiding any spillage of an unrecognized malignant component and avoiding recurrence due to incomplete resection after OSS (14). Ovarian-sparing surgery (OSS) should, however, be highly considered because of the risk of fertility impairment with a cumulative estimated risk of recurrence of $10 \%$ to $20 \%(8,16)$.

To better consider the possibility of proposing ovarian-sparing surgery, we report a nationwide cohort of pediatric OMTs and analyze the risk factors for a second event.

\section{Materials and Methods}


Population

A nationwide retrospective multicentric review of all pediatric cases with OMT treated between January 2007 and December 2016 was conducted in France. Eligible patients were females under 18 years of age at diagnosis who underwent surgery for histologically proven OMT. Cases were extracted by analyzing local and national databases of theSociété Française de lutte contre les Cancers et les leucémies de l'Enfant (SFCE), the "Societe Francaise de Chirurgie pediatrique" (SFCP), the FrePSO (French Pediatric Surgeons Oncology) group, the "Comité de Coordination de Pathologie Pédiatrique et Périnatale" (CCOPPP) and the FRACTURE (Groupe Français des tumeurs rares ). Data on clinical features, imaging and laboratory studies, surgical reports, pathological diagnoses and outcomes were collected. Information on the management of second events and long-term morbidity was also retrieved through the reports of the postoperative consultations where abdominal ultrasound was carried out. In the absence of consensus in the literature (17-19), the schedule of this follow-up (FU) program differed from one center to another.

We defined persistent first complete remission (CR1) as patients who did not experience any second event after initial surgery during the FU and second (CR2) and third (CR3) complete remission as patients in remission after one or two second events. A second event was considered when a new ovarian mass, suggesting a new tumor, occurred in the same or in the contralateral ovary after initial surgery. Pathological analysis should be documented when a second surgery is carried out or highly suggestive on imaging and biological work-up if the management is limited to surveillance.

Statistical analysis

Baseline characteristics of the studied population were described as medians (ranges) for quantitative variables and numbers (percentages) for qualitative variables. The time to OMT second events was plotted using Kaplan-Meier curves. Baseline factors associated with OMT second events were identified by univariate analysis using the log-rank test if they were qualitative or by the Cox model if quantitative (such as age at diagnosis). Univariate analysis on the type of surgery was based on the population without missing data (6 cases excluded). Factors that were associated with a $\mathrm{p}<0.10$ in univariate analysis were considered in a multivariate Cox model using a stepwise procedure for entering and staying in the model. All statistical analyses were performed with SAS software V9.4 (SAS Institute, NC, Cary), and a p-value $<0.05$ was considered to denote statistical significance.

This study was supported by the board of ethics committee (CLERS) and conducted in accordance with the Declaration of Helsinki. Institutional review board approval was obtained.

\section{Results}

Overall, 350 children were identified from 18 centers. Table 1 describes the patient and tumor characteristics. The median age at tumor diagnosis was 11 years (range, 0-17). Data on OMT affecting another family member, most frequently at the first-degree level (80\%), was retrieved in 10 cases (3\%). None involved three consecutive generations. Genetic investigations were conducted in seven cases, but no anomalies were identified. Past medical history revealed a known germinal genetic anomaly in two children without other OMTs in the family: STIM1 pathogenic variant in exon 7 (one case) and familial SNX10pathogenic variant (one case).

The most frequent revealing symptom was abdominal pain in $61 \%$ of cases, $40 \%$ being related to adnexal torsion. Large palpable masses (27\%), urinary disorders (6\%) and transit disorders (22\%) were the other symptoms, and these were explained by the tumor volume and local compression. Also, menstrual cycle disorders were noted (4\%). Data on pubertal status were available for $51 \%$ of females, and $59 \%$ of them had achieved puberty with onset menarche. An early puberty's context was observed in 12 cases (3\%). These patients presented a median age of nine years at OMT diagnosis. For seven of them, the early puberty was considered unrelated to the OMT. OMT was incidentally diagnosed in $25 \%$ of cases. Data on serum tumor markers (AFP and HCG) were available in 330 cases, being negative in 325 cases (98\%). A low increase in AFP was noted in five cases (1.5\%). Eighteen patients $(5 \%)$ presented synchronous bilateral OMT at 
diagnosis.

Surgical procedures were carried out with a median delay of 10.5 days (range, 0-1504) after diagnosis, $72 \%$ of them being planned and $28 \%$ performed as an emergency. Adnexal torsions $(n=87)$ represented $76 \%$ of emergency surgeries and were managed by laparoscopic detorsion associated with tumor resection in oneor two-step procedures. TO was performed in $57 \%$ of adnexal torsion cases. Tables 1 and 2 describe the initial surgical management characteristics of the whole cohort. Laparotomy was performed in $83 \%$ of cases, was performed as a single procedure in $53 \%$ of cases, was associated with initial exploratory laparoscopy in $32 \%$ of cases. Fifteen percent of the cohort underwent exclusive laparoscopy. OSS was performed in $56 \%$ of unilateral OMTs and in all bilateral OMTs. Considering the whole cohort, OSS was performed in 59\% of cases $(n=208)$, and TO was performed in the other cases $(n=142)$. TO was performed by laparotomy associated or not to laparoscopy in $87 \%$ of cases and by laparoscopy in $13 \%$ (Table 2).

Preoperative rupture was suspected and confirmed during surgery in eight cases. Perioperative tumor rupture occurred in 23 cases $(7 \%)$. If perioperative rupture was more frequent when laparoscopy was performed (11.3\%), this was not significant $(\mathrm{p}=0.09)$ (Table 2$)$.

All tumors underwent macroscopic complete resection independently of the surgical approach. No peritoneal tumor spreading was observed on peritoneal cytologic examination of the collected fluids, which was performed systematically in all cases. Pathologic examination of the specimen revealed minor associated immature malignant components in seven cases, all of which exhibited moderate serum AFP elevation.

\section{Outcome}

After a median FU of 25.5 months since the first surgery (range 0-88), 29 tumor events occurred (8.3\%) after a median delay of 30.5 months (range, 1-88) from diagnosis. The initial surgical management of these recurrent cases was TO in 10 cases (34\%) and OSS in 19 cases (66\%) (Table 1). New lesions occurred on the same ovary in eight patients $(28 \%)$, on the contralateral ovary in 18 patients $(62 \%)$, and on both ovaries in three patients (10\%). Among these ipsilateral new lesions, one case had a juvenile cell granulosa tumor (JCGT) on the ipsilateral ovary 47 months after OSS of the OMT. A contralateral second event occurred in $48 \%$ of cases after surgical management by OSS. Treatment of recurrences was surgery in 23 out of 29 cases and could be conservative in $82 \%$ of cases (OSS/TO; 19/4) (Table 3). Four of them benefited from cryopreservation of the remaining ovarian healthy tissue. In these patients, only one was managed by TO at the first surgery. OSS was performed on all of them at the second surgery. Six patients (21\%) were not operated on for this second event and benefited from a regular wait-and-see strategy. At a median FU of 9.5 months (range: 0,65 ), these patients did not present any tumor progression. JCGT was treated by TO with salpingectomy, leading to complete microscopic surgical resection (FIGO stage Ia) without any adjuvant treatment. This patient was in CR2 four years after this second event. Three patients presented a third event, affecting both ovaries in each subject. Two of them were then treated by OSS and one by TO.

Overall, at the end of FU, 321 patients remained in CR1 (91.7\%), 20 in CR2 (5.7\%), and three in CR3 $(0.9 \%)$, and six had stable disease (1.7\%). All are alive at the end of FU (OS 100\%). The 2 year-EFS was 95.2\% [95\% CI, 91.7 - 97.3] (Fig. 1A). At the last FU, 18 patients had two reduced ovaries after unique or multiple OSS (5\%), and 132 patients (38\%) had one whole ovary remaining after TO carried out at the first or second surgery. No patient needed bilateral oophorectomy (Supplemental Appendix 1).

Risk factors analysis

In univariate analysis, increase of age, large palpable mass, bilateral synchronous forms at diagnosis and perioperative rupture had a statistical impact on the risk of second tumor events (Table 1, Fig. 1B and C). In the multivariate analysis, the same variables except age remained prognostic (Table 1). Neither the type of surgical approach (laparoscopy and laparotomy) nor the type of tumor resection (TO and OSS) influenced the risk of recurrence (Table 1). In the subgroup that benefited from OSS, the second event was not influenced by the initial surgical approach. Perioperative rupture was considered a risk factor for a second event, with a 2-year EFS of $85.0 \%$ [95\% CI, $60.4-94.9]$ vs. 96.0\% [95\% CI, 92.3 - 98.0] (Fig. 1B). Twenty-four percent 
of patients with second events experienced a perioperative tumor rupture during an OSS procedure (Table 3 ). The second event was, however, on the contralateral ovary in all cases except two, where recurrence was bilateral or with JCGT in the ipsilateral ovary. Perioperative rupture during OSS was thus not associated with a second event in the ipsilateral ovary $(\mathrm{p}=0.41)$.

\section{Discussion}

This large nationwide study showed that a conservative approach is possible in OMT, with $60 \%$ of patients who kept at least one ovary. The incidence of recurrence was low at $8.3 \%$ and was not influenced by the type of initial surgical approach or the type of tumor resection. Risk factors for recurrence were intrinsic to the tumor features, such as a large palpable mass and bilateral synchronous forms at diagnosis.

The clinical presentation of OMT in our series did not differ from the literature $(1,3,4,14)$, with the most frequent revealing symptom being abdominal pain in $61 \%$ of cases. One-third of patients underwent emergency surgery and revealed adnexal torsion in $40 \%$ of cases, which represents $25 \%$ of the whole cohort. This incidence is relatively high compared to the $3 \%$ to $16 \%$ of cases in cohorts including both adults and children in the literature $(6-8,15,20,21)$. A palpable mass was present in $27 \%$ of cases in our cohort. Data on the exact size of the lesion was not available for all patients, and the retrospective nature of our study precludes any analysis of the risk of recurrence according to tumor size. Nevertheless, the association of a palpable mass with a risk of recurrence as an independent variable suggests that the size of the teratoma may influence the risk of recurrence.

Elevations in AFP and HCG are considered features of a malignant GCT, but in a case of OMT, these tumor markers are usually normal $(14,15)$. An elevation in AFP was observed in five cases in our series and may be related to the presence of a small immature teratoma or a differentiated liver component $(3,23)$. This possibility prompts avoidance of any spillage during teratoma surgery because of the possible association with an immature component, which was not found at the preoperative staging.

Our experience showed, as others, that laparoscopy and laparotomy can both be safely practiced for OMT surgery without any influence on OMT recurrence $(19,24)$. Laparoscopy has the advantages of decreasing postoperative pain, complications, and length of hospitalization $(6,8,20,22,25)$. It also minimizes postoperative adhesions, which may have an impact on fertility $(6,7,24)$. All of these benefits promote laparoscopy as the first surgical approach in adults $(6,20,21)$. However, more tumor rupture and spillage are described during laparoscopy $(6,26)$, and this risk is increased when OSS is considered.

In our study, laparotomy with or without preceding laparoscopy was performed in $83 \%$ of cases and comprised OSS in $58 \%$ of these cases. Laparoscopy was performed only in $15 \%$ of cases, precluding any analysis of the influence of the type of surgery on the second event in this group. In the whole cohort, however, OSS did not increase the risk of a second event. In the literature, unilateral oophorectomy seems to have no impact on puberty development (27) but could advance menopause by 1.1 to 1.8 years with the health consequences of estrogen deprivation $(16,17,28,29)$. Bilateral forms and second events, reported in $5 \%$ and $8.3 \%$ of cases in our cohort, may lead to additional amputation of the ovarian tissue. All these features favor conservative surgery in OMT to preserve the ovarian tissue and reserve as much as possible $(8,11,14,25,30)$. In our series, all patients maintained at least one ovary even after recurrence. Additionally, fertility preservation should be contemplated in cases of bilateral forms at diagnosis or of a second event after surgery (31). In this case of benign indications at the postpubertal stage, oocyte cryopreservation is still the highest-yield strategy to offer (31). Cryopreservation of ovarian tissue is also an option and remains the only one before the onset of puberty (31-33).

The incidence of metachronous OMT was $8.3 \%$ in our cohort, slightly lower than the 10 to $20 \%$ reported in the literature $(6,8,17,19)$. Recurrence was observed mainly on the contralateral ovary $(62 \%)$ or on both ovaries (10\%). The second tumor occurred on the same ovary in only $28 \%$ of recurrent cases, an observation already made in other reports $(6,8,17)$. This suggests that metachronous OMT is more a new event than a local recurrence of the primary tumor. This hypothesis is supported by DNA profile analysis of OMT at diagnosis and after relapse (34) and PCR analysis of a case with synchronous bilateral OMT (2). Multiple 
synchronous forms and the observation in our study that bilateral forms are at risk of a second event may suggest a genetic origin in OMT (6). Data on the presence of a familial history was retrieved in only three percent of cases in our cohort. This incidence is certainly higher, as the questioning for familial history is not systematic and information on this is difficult to retrieve. To date, no specific germinal gene pathogenic variant background has ever been documented in such families, as in our cohort $(15,35,36)$.

Risk factors for a second event related in our study were also the occurrence of a perioperative rupture. As most of the recurrences were on the contralateral ovary, it is difficult to interpret and could be biased by confounding factors such as the size of the lesion, although no significant association was observed between perioperative rupture and palpable mass. Other studies did not find perioperative rupture to be a risk factor for recurrence in an adult population $(7,37)$.

As the EFS curve did not show any plateau, it suggests the need for prolonged surveillance after surgery (18). Considering the median time to a second event of 30.5 months and the slow growth rate of this benign tumor, we propose a pelvic and abdominal US exam every 6 months during the five years following initial surgery. Patients and family should be informed of the risk of recurrence and of the importance of consulting in cases of pelvic symptoms. These patients have amputation of their ovarian capital and may also present adnexal torsion on a functional cyst or tumor recurrence, even years after the initial event. They must therefore be considered at risk for premature ovarian failure.

In conclusion, despite the limitations linked to the retrospective nature of our analysis, these results support a conservative approach for OMTs in children. The rationale for surgery is the risk of adnexal torsion and the natural growth of the teratoma, which may preclude any possibility of OSS $(6,17,20)$. In an emergency, laparoscopy is a good option, particularly when adnexal torsion is observed; simple detorsion is recommended with a second-step resection surgery. When planned resection is performed, OSS should be preferred, and laparoscopy should be considered only if there is no doubt on the benign nature of the lesion. If this is not the case, TO should be performed preferentially with a laparotomy preceded by a laparoscopic exploration of the peritoneum, and peritoneal fluid sending for analysis. Laparoscopy should be proposed only if the removal of the tumor can be performed without rupture, avoiding morcellation of the specimen to allow proper pathological analysis of the tumor (38). Finally, the observation of multiple bilateral lesions and/or familial history as well as the contralateral side of most metachronous lesions suggest a genetic predisposing background and invite wider genetic investigations in pediatric OMTs.

\section{Acknowledgements}

The authors gratefully acknowledge patients and their families, pediatric surgeons, pathologists and the French Germ Cell Tumors SFCE committee.

\section{Disclosure of interest}

Authors have nothing to disclose.

\section{Contribution to Authorship}

All of the authors mentioned have actively participated in this paper. DELEHAYE F, ROD J, SARNACKI $\mathrm{S}$ and ORBACH D created the concept of this study, coordinated the data collection and analyses, and drafted mainly this paper. Authors working in pathologist departments let us to extract all the patients to review (DIJOUD F, WACRENIER A, CROUE A, POMMEPUY I, GALMICHE L). Surgeons and oncologist pediatricians participated in the data collection (DELEHAYE F, CHEIKHELARD A, ROUGER J, FAURECONTER C, HAMEURY F, AUBRY E, HABONIMANA E, DUCHESNE C, JOSEPH S, ALLIOT H, SCALABRE A, CHAUSSY Y, PODEVIN G, HARAUX E, BALLOUHEY Q, LAVRAND F, PEYCELON M, IRTAN S, GUERIN F, DARIEL A, BORIONNE C). Statistical analysis was carried out by PARIENTI JJ. All the co-authors revised the article to improve it. All of the authors approved the final version of the paper that we submit to publication to BJOG.

\section{Details of Ethics Approval}


Approval by the Ethics committee (CLERS Comité Local d'Ethique de la Recherche en Santé ) of the University Hospital of Caen Normandy, Caen, France.

Date of approval: 23/05/2019

Reference number: ID444

Funding

No specific funding sources for this work. The French Fracture very rare cancer database is supported by a grant from SFCE/Imagine for Margo.

\section{References}

1. Brown MF, Hebra A, McGeehin K, Ross AJ. Ovarian masses in children: a review of 91 cases of malignant and benign masses. J Pediatr Surg 1993;28:930-2.

2. Wang WC, Lai YC. Evidence of metachronous development of ovarian teratomas: a case report of bilateral mature cystic teratomas of the ovaries and systematic literature review. J Ovarian Res 2017;10:17.

3. Zhang M, Jiang W, Li G, Xu C. Ovarian masses in children and adolescents - an analysis of 521 clinical cases. J Pediatr Adolesc Gynecol 2014;27:e73-7.

4. Lo Curto M, D'Angelo P, Cecchetto G, Klersy C, Dall'Igna P, Federico A, et al. Mature and immature teratomas: results of the first paediatric Italian study. Pediatr Surg Int 2007;23:315-22.

5. Schneider DT, Calaminus G, Koch S, Teske C, Schmidt P, Haas RJ, et al. Epidemiologic analysis of 1,442 children and adolescents registered in the German germ cell tumor protocols. Pediatr Blood Cancer 2003;42:169-75.

6. O'Neill KE, Cooper AR. The approach to ovarian dermoids in adolescents and young women. J Pediatr Adolesc Gynecol 2011;24:176-80.

7. Tokmak A, Guzel AI, Erkilinc S, Yesilyurt H, Zergeroglu S, Erkaya S, et al. Factors affecting recurrence after surgery for ovarian mature cystic teratoma. J Obstet Gynaecol 2015;36:289-92.

8. Özer A, Kıran H. Analysis of the factors determining the type of surgical procedure in mature cystic teratomas. Ginekol Polska 2017;88:134-7.

9. Templeman CL, Hertweck SP, Scheetz JP, Perlman SE, Fallat ME. The management of mature cystic teratomas in children and adolescents: a retrospective analysis. Hum Reprod 2000;15:2669-72.

10. Hermans AJ, Kluivers KB, Janssen LM, Siebers AG, Wijnen MHWA, Bulten J, et al. Adnexal masses in children, adolescents and women of reproductive age in the Netherlands: a nationwide population-based cohort study. Gynecol Oncol 2016;143:93-7.

11. Saba L, Guerriero S, Sulcis R, Virgilio B, Melis G, Mallarini G. Mature and immature ovarian teratomas: CT, US and MR imaging characteristics. Eur J Radiol 2009;72:454-63.

12. Lala SV, Strubel N. Ovarian neoplasms of childhood. Pediatr Radiol 2019;49:1463-75.

13. Oltmann SC, Garcia N, Barber R, Huang R, Hicks B, Fischer A. Can we preoperatively risk stratify ovarian masses for malignancy? J Pediatr Surg 2010;45:130-4.

14. Renaud EJ, Sømme S, Islam S, Cameron DB, Gates RL, Williams RF, et al. Ovarian masses in the child and adolescent: an American pediatric surgical association outcomes and evidence-based practice committee systematic review. J Pediatr Surg 2019;54:369-77.

15. Braungart S, McCullagh M. Management of familial ovarian Teratoma: the need for guidance. Eur J Pediatr Surg Rep 2016;04:31-3. 
16. Rosendahl M, Simonsen MK, Kjer JJ. The influence of unilateral oophorectomy on the age of menopause. Climacteric 2017;20:540-4.

17. Chabaud-Williamson M, Netchine I, Fasola S, Larroquet M, Lenoir M, Patte C, et al. Ovarian-sparing surgery for ovarian teratoma in children. Pediatr Blood Cancer 2011;57:429-34.

18. Łuczak J, Bagłaj M, Dryjański P. What recent primary studies tell us about ovarian teratomas in children: a scoping review. Cancer Metastasis Rev 2020;39:321-9.

19. Rogers EM, Allen L, Kives S. The recurrence rate of ovarian dermoid cysts in pediatric and adolescent girls. J Pediatr Adolesc Gynecol 2014;27:222-6.

20. Sinha A, Ewies AAA. Ovarian mature cystic teratoma: challenges of surgical management. Obstet Gynecol Int 2016;2016:1-7.

21. Ayhan A, Bukulmez O, Genc C, Karamursel BS, Ayhan A. Mature cystic teratomas of the ovary: case series from one institution over 34 years. Eur J Obstet Gynecol Reprod Biol 2000;88:153-7.

22. Audebert A. Kyste de l'ovaire de l'adolescente. Méd Reprod 2012;15:37886.

23. Children's Cancer and Leukaemia Group. Interim guidelines for the treatment of extracranial germ cell tumours in children and adolescents. Leicester, 2018.

24. Medeiros LR, Stein AT, Fachel J, Garry R, Furness S. Laparoscopy versus laparotomy for benign ovarian tumor: a systematic review and meta-analysis. Int J Gynecol Cancer 2008;18:387-99.

25. Kondo W, Bourdel N, Cotte B, Tran X, Botchorishvili R, Jardon K, et al. Does prevention of intraperitoneal spillage when removing a dermoid cyst prevent granulomatous peritonitis? BJOG Int J Obstet Gynaecol 2010;117:1027-30.

26. Savasi I, Lacy JA, Gerstle JT, Stephens D, Kives S, Allen L. Management of ovarian dermoid cysts in the pediatric and adolescent population. J Pediatr Adolesc Gynecol 2009;22:360-4.

27. Zhai A, Axt J, Hamilton EC, Koehler E, Lovvorn HN. Assessing gonadal function after childhood ovarian surgery. J Pediatr Surg 2012;47:1272-9.

28. Yasui T, Hayashi K, Mizunuma H, Kubota T, Aso T, Matsumura Y, et al. Factors associated with premature ovarian failure, early menopause and earlier onset of menopause in Japanese women. Maturitas 2012;72:249-55.

29. Bjelland EK, Wilkosz P, Tanbo TG, Eskild A. Is unilateral oophorectomy associated with age at menopause? A population study (the HUNT2 Survey). Hum Reprod 2014;29:835-41.

30. Braungart S, Craigie RJ, Farrelly P, Losty PD. Ovarian tumors in children: how common are lesion recurrence and metachronous disease? A UK CCLG Surgeons Cancer Group nationwide study. J Pediatr Surg 2020;55:2026-9.

31. Donnez J, Dolmans MM. Fertility preservation in women. N Engl J Med 2017;377:1657-65.

32. Dudzinski DM. Ethical issues in fertility preservation for adolescent cancer survivors: oocyte and ovarian tissue cryopreservation. J Pediatr Adolesc Gynecol 2004;17:97-102.

33. McDougall RJ, Gillam L, Delany C, Jayasinghe Y. Ethics of fertility preservation for prepubertal children: should clinicians offer procedures where efficacy is largely unproven? J Med Ethics 2017;44:27-31.

34. Surti U, Hoffner L, Chakravarti A, Ferrell RE. Genetics and biology of human ovarian teratomas. I. Cytogenetic analysis and mechanism of origin. Am J Hum Genet 1990;47:63543.

35. Stattin EL, Henning P, Klar J, McDermott E, Stecksen-Blicks C, Sandström P-E, et al. SNX10 gene mutation leading to osteopetrosis with dysfunctional osteoclasts. Sci Rep 2017;7:3012. 
36. Lacruz RS, Feske S. Diseases caused by mutations inORAI1andSTIM1. Ann N Y Acad Sci 2015;1356:4579.

37. Taskinen S, Urtane A, Fagerholm R, Lohi J, Taskinen M. Metachronous benign ovarian tumors are not uncommon in children. J Pediatr Surg 2014;49:543-5.

38. Fresneau B, Orbach D, Faure-Conter C, Verité C, Castex MP, Kalfa N, et al. Sex-cord stromal tumors in children and teenagers: results of the TGM-95 study. Pediatr Blood Cancer 2015;62:2114-9.

\section{Figure and Tables legends}

Fig. 1. A: Event-free survival of the 350 patients with OMTs B: Impact of perioperative rupture on EFS C: Impact of bilateral forms of OMT at diagnosis on EFS

Table 1. Clinical, biological and surgical characteristics of a nationwide pediatric cohort of patients operated on for OMTs.

HR: hazard ratio; OMT: ovarian mature teratoma

Table 2. Repartition of perioperative rupture and second event according to initial surgical approach*.

*Exclusion of patients with missing data on the type of surgery $(\mathrm{N}=6)$

OSS: ovarian-sparing surgery; TO: total oophorectomy

Table 3. Description of all second events and their management.

*: familial history of OMT; ${ }^{\circ}$ bilateral OMT at diagnosis; JCGT: juvenile cell granulosa tumor; OSS: ovariansparing surgery; TO: total oophorectomy; CR: complete remission

Supplemental appendix 1. Amount of remaining ovarian tissue according to the type of initial surgery at the last follow-up.

\section{Hosted file}

Figure 1.pdf available at https://authorea.com/users/408121/articles/518264-lessons-from-alarge-nationwide-study-of-350-children-with-ovarian-mature-teratoma-a-plea-for-ovariansparing-surgery

\section{Hosted file}

Table 1.pdf available at https://authorea.com/users/408121/articles/518264-lessons-from-alarge-nationwide-study-of-350-children-with-ovarian-mature-teratoma-a-plea-for-ovariansparing-surgery

\section{Hosted file}

Table 2.pdf available at https://authorea.com/users/408121/articles/518264-lessons-from-alarge-nationwide-study-of-350-children-with-ovarian-mature-teratoma-a-plea-for-ovariansparing-surgery

\section{Hosted file}

Table_3.pdf available at https://authorea.com/users/408121/articles/518264-lessons-from-alarge-nationwide-study-of-350-children-with-ovarian-mature-teratoma-a-plea-for-ovariansparing-surgery

\section{Hosted file}

Supplemental Table 1.pdf available at https://authorea.com/users/408121/articles/518264lessons-from-a-large-nationwide-study-of-350-children-with-ovarian-mature-teratoma-aplea-for-ovarian-sparing-surgery 